\title{
Squeaky clean?
}

\section{Phil Wiffen}

'Squeaky clean' conveys two meanings, it can refer to something that is so clean that it squeaks when rubbed, like hair after washing. It also has taken on the meaning of something creating a virtuous and wholesome image, though this is sometimes used in a derogatory way. This issue of the journal contains what could be considered a very pro-industry view on the use of biosimilars in transplantation (page 302). However, we have set this alongside a much more pragmatic hospital pharmacy view as well as some interesting articles on legal, economic and selection issues.

Some correspondence into EJHP has raised concerns that the journal is too proPharma, citing one or two recent articles that seem to put an industry view point. I reject that claim but will seek to manage a balance between the pro-Pharma and

Correspondence to Professor Phil Wiffen, Pain Research Unit, Churchill Hospital, Old Rd, Oxford OX3 7LE, UK; phil.wiffen@ndcn.ox.ac.uk
anti-Pharma lobbies that seem to exist among hospital pharmacists. My perspective is that Pharma is essential to much of what we do, especially as the majority of the tools we use in terms of licenced medicines are Pharma produced. On the other hand there have been notable errors of judgement by Pharma in the past in terms of massaging data on clinical trials and not being as transparent as many of us would like. Many years ago I became aware of a Pharma advert being used when I was working Indonesia which stated 'Lomotil (NB now discontinued) as used by the Apollo astronauts' the promotion was aimed at people who developed diarrhoea from contaminated food or water so hardly relevant. Industry behaviour such as this and around clinical trials has led to popular Pharma bashing such as 'Bad Pharma' by Ben Goldacre. Many of his examples are old but we need to be aware of what he says. The pitch is somewhat muddied by the issue of professional development and
Pharma is still willing to sponsor events and also fund travel, accommodation and registration to the major pharmacy conferences. At what cost?

The EJHP editorial team have to be vigilant; although we don't always agree on whether a particular article is too promotional, what is clear is that we are seeking to be vigilant. Good publication ethics are vitally important. Any relationship which involves writing with Pharma or any lobby group must be clearly stated and there should always be the freedom to state a view without veto from the related industry interest. Authors' names should be representative of genuine work and the journal will not accept papers that are ghost written.

Pharmacists in general do have the skills to detect an article that is uncomfortably promotional, but it is a skill that must be nurtured and developed. This is why an evidence-based approach is so helpful.

So is EJHP squeaky clean? You decide!

\section{Competing interests None.}

Provenance and peer review Commissioned; internally peer reviewed.

To cite Wiffen P. Eur J Hosp Pharm 2013;20:261.

Eur J Hosp Pharm 2013;20:261.

doi:10.1136/ejhpharm-2013-000387 